\title{
Pazarlama Kaynaklarına En Uygun Rekabetçi Pazarlama Stratejisinin Belirlenmesi: Kış Turizmi Otellerine Yönelik Bir Uygulama
}

\author{
Determining of the Most Convenient Marketing Competition Strategy towards \\ Marketing Resource: An Implementation to Winter Tourism Hotels
}

Mustafa Kemal YILMAZ' ${ }^{1}$ Enes Emre BAŞAR ${ }^{1}$, Hakan PABUÇCU ${ }^{1}$

\section{ÖZET}

Issletmelerin rekabet avantajı elde etmelerinde, sahip olduklar pazarlama kaynakları belirleyici olmaktadır. Buradan hareketle bu çalışmada, kış turizmi kapsamında faaliyet gösteren otel işletmelerinin sahip oldukları pazarlama kaynaklarına en uygun rekabet stratejilerinin belirlenmesi amaçlanmıştır. Bu bağlamda, Doğu Anadolu Bölgesi'nde kış turizmi faaliyetleri yapılan illerde 3 yıldız ve üstü otel işletmelerinden 20 yönetici veya işletme sahibi ile görüşülmüştür. Elde edilen verilere, çok amaçlı karar verme yöntemlerinden olan analitik hiyerarşi süreci yaklaşımı (AHS) ve alternatiflerin önem sıralamasının yapıldığı bulanık TOPSIS yöntemi uygulanmıştır. Sonuçlar, işletmelerin rekabet avantajı sağlamalarında en çok etkisi olan pazarlama kaynağının müşteri ilişkileri kapasitesi olduğunu göstermiştir. Bununla birlikte, rekabetçi pazarlama stratejisi uygulamanın, farklılaşma stratejisi ile gerçekleşebileceği de araştırmanın diğer önemli sonucudur.

Anahtar kelimeler: Pazarlama kaynakları, rekabet stratejileri, çok kriterli karar verme, kış turizmi, Doğu Anadolu Bölgesi, analitik hiyerarşi süreci, Bulanık TOPSIS.

\section{GíRiş}

Dünyada her yıl milyonlarca kişi, eğlenmek, dinlenmek ve spor yapmak gibi birçok nedenlerle çeşitli turizm faaliyetlerine katılmaktadır. Nüfus artışları, gelir ve eğitim düzeyinin yükselmesi gibi nedenlerle turizm faaliyetlerine olan talep gün geçtikçe artmaktadır. Talep miktarının artışı ile birlikte, turizm faaliyetlerinden beklentiler de artmıştır. Bu da turizm çeşitliliğini beraberinde getirmiştir (Manap, 2006). Bu bağlamda kış turizmi, dünyada ve Türkiye'de oldukça önemli bir yere sahiptir. Son yıllarda, Türkiye'nin birçok bölgesinde olduğu gibi, Doğu Anadolu Bölgesi'nde de kış turizmine yönelik yapılan yatırımlar giderek artmıştır. Bu durum, kış turizminde faaliyet gösteren otel işletmelerinin aralarındaki rekabetin giderek yoğunlaşmasını da beraberinde getirmiştir. Zorlu bir rekabet ortamında ise işletmeler, rekabet avantajı elde etmenin yollarını aramaktadırlar. Bu nedenle, rekabet

\begin{abstract}
Marketing resources which they have play a determining role for companies to take advantage on competing. From this point of view, this study aims to determine the most suitable competitive strategies for hotel businesses operating in winter tourism in parallel with the marketing resources they have. In this context, 20 managers/owners of three-or morestar winter hotel businesses located in Eastern Anatolia Region of Turkey are interviewed. The decision method based on the expert opinion of AHP approach and fuzzy TOPSIS method which ranking the importance of alternative are applied to the obtained data. Findings show that the most effective marketing resource on companies to take advantage on competing is capacity of customer relations. In addition to this finding, the other important finding of research is that according to hotels' owners/managers, differentiation strategy is the most useful competation strategy.
\end{abstract}

Keywords: Marketing resources, compatitive strategy, multi criteria decision making, winter tourism, East Anatolia Region, Analytic Hierarchy Process, Fuzzy TOPSIS

avantajı sağlamak isteyen otel işletmeleri, sahip oldukları kaynakları, pazarlama stratejileri geliştirmek için kullanmaktadırlar.

Kaynak temelli yaklaşım, son yıllarda pazarlama stratejileri alanında en fazla incelenen konulardan biridir (Phillips vd. 2001). Bu çalışmalarda, firmaların rekabet avantajı yaratarak işletme performanslarını artırmalarında, pazarlama kaynaklarının büyük bir role sahip olduğu tespit edilmiştir (Lin ve Wu, 2008). Firmaların pazarlama kaynaklarından yararlanarak daha rekabetçi bir pazar konumuna sahip olmaları, kaynaklarını rakiplerden daha başarılı bir şekilde kullanmalarına bağlıdır (Hooley vd., 2005). Yani kaynakların, stratejik bir yaklaşımla en yüksek faydayı sağlayacak şekilde kullanılması önem arz etmektedir (Lin ve Wu, 2008). Öte yandan, stratejik pazarlama alanında problemlerin giderek daha karmaşık hale gelmesi, kapsamlı ve doğru kararların alınmasını da 
güçleştirmektedir. Bu bağlamda çok kriterli karar verme teknikleri, doğrudan seçim yapmanın zor olduğu karmaşık durumlarda, doğru kararlar almak için kullanılmaktadır (Lin ve Wu, 2008). Çok kriterli karar verme tekniklerinin temel prensibi, kararların birçok kritere bağlı olmasıdır (Saaty, 1994). Analitik hiyerarşi süreci (AHS) ise karmaşık problemleri; tümevarım yöntemiyle ayrıştırarak, hiyerarşik bir yapı içerisinde çeşitli faktörler ve bu faktörlere bağlı alt boyutlar oluşturarak karşılaştırılmasını sağlayan çok kriterli bir karar verme yöntemidir (Saaty, 2008). Diğer bir ifadeyle AHS, matematiksel ve objektif bir karar verme aracı olarak, belirsiz ve çok kriterli problemleri çözmek için kullanılmaktadır (Udo, 2000). Ayrıca karar aşamasında insan düşüncesindeki belirsizlik ve öznelliğin ifade edilmesi bulanık mantık kuralları ve dilsel ifadeler kullanılarak başarılı bir şekilde yapılmaktadır. Bu nedenle uygulamanın son aşamasında Bulanık TOPSIS yöntemi tercih edilmiştir (Büyüközkan ve Çiftçi, 2012)

Bu çalışmada, Doğu Anadolu bölgesinde faaliyet gösteren kış turizmi otellerinin sahip oldukları pazarlama kaynakları ve bu kaynaklarla uyumlu rekabet stratejilerinin belirlenmesi amaçlanmıştır. İlk olarak, pazarlama kaynakları ve rekabet stratejileri konularına yönelik literatür incelemesi yapılmıştır. Daha sonra, Doğu Anadolu Bölgesi'nde kış turizminin yapıldığı illerdeki 20 otelin yönetici/sahipleri ile yüz yüze görüşme tekniği ile görüşülmüş, elde edilen verilere AHS ve TOPSIS yöntemi uygulanmıştır. Son olarak elde edilen bulgular yorumlanmıştır.

\section{KAVRAMSAL ÇERÇEVE}

\subsection{Kaynak Temelli Yaklaşım ve Pazarlama Kaynakları}

Kaynak temelli yaklaşım, ilk olarak 1980'li yıllarda ortaya çıkmıştır (Penrose 1996). O zamanlarda baskın olan paradigma; kaynakların, her firmanın kar potansiyeline göre belirlenen üretim yönlü faktörler olduğudur (Porter, 1979). Fakat daha sonraki araştırmalarda firma kaynakları, çok çeşitli faktörlerin birleşimi olarak ele alınmıştır (Wernerfelt 1984). Wernerfelt'in (1984) çalışması, kaynak temelli yaklaşıma ilk büyük katkıyı sunmuştur (Kozlenkova vd., 2014). Lippman ve Rumelt (1982) ve Barney (1986) tarafından yapılan araştırmalar, teorinin gelişmesini sağlamıştır. Barney (1991) ise konunun temel ilkelerini ve karakteristiklerini tanımlamıştır. Buna göre kaynaklar; varlıkların, kapasitelerin, süreçlerin, firma niteliklerinin ve bilginin birleşimidir. İşletmelerin sahip olduğu kaynakların farklııı göstermesi ve farklı kaynaklara sahip işletmelerin performanslarının da farklılaşması, bu kaynakların rekabet avantajı yaratılmasında etkili olduklarını göstermektedir. Yani kaynaklar, üstün müşteri değeri yaratarak firmalara rekabetçi avantajlar sağlayan birleştirilmiş özellikler olarak görülmektedir (Barney,
1991). Rekabetçi avantajların sürdürülebilirliği ise kaynakların taklit edilmesini önleyici tedbirler almaya bağlıdır (Hooley vd., 2005). Bu tedbirler ise belirsizlik (avantajın nasıl elde edildiğinin açıklanmaması), karmaşıklık (kaynakların birbirleriyle çok fazla etkileşimlerinin olması) ve yasal engellerdir (patentler, telif hakları vb.) (Reed ve DeFillippi, 1990).

Kaynak temelli yaklaşım, pazarlama literatüründe pazarlama kaynakları olarak da ifade edilmektedir (Gupta ve Steenburgh, 2008; Kozlenkova vd., 2014). $\mathrm{Bu}$ yaklaşım, işletmelerin pazarda değer yaratmasını sağlayan kaynakları ifade etmektedir (Hooley vd., 2005). Pazarlama kaynakları, işletmelerin pazarda rekabet avantajı sağlamak için uyguladıkları; soyut, somut, fiziksel, beşeri, entelektüel ve ilişkisel nitelikler olarak tanımlanmaktadır (Srivastava, 1998). Hooley vd. (2005) pazarlama kaynaklarını, pazar temelli kaynaklar ve pazarlama destek kaynakları olarak ikiye ayırmıştır. Pazar temelli kaynaklar; müşteri ilişkileri kapasitesi, pazar inovasyon kapasitesi, insan kaynakları değeri ve firma ünü değerinden oluşmaktadır. Pazar temelli kaynaklar, rekabet avantajı sağlamakta doğrudan etkilidirler. Pazarlama destek kaynakları ise pazarlama faaliyetlerini destekleyen ve firmaların rekabet avantajı sağlamalarında dolaylı etkileri olan kaynaklardır. Pazarlama destek kaynakları; yönetim kapasitesi ve pazar yönlülük olmak üzere ikiye ayrılır. Ancak Deshpande ve Webster Jr (1989) ve Hunt ve Morgan (1995), pazar yönlülüğün doğrudan pazarlama kaynakları içerisinde yer almadığını, yönetim kapasitesi üzerinden dolaylı bir etkiye sahip olduğunu ileri sürmüşlerdir. Benzer şekilde, Lin vd. (2009) ve Wu vd. (2010) de çalışmalarında pazar yönlülüğü, yönetim kapasitesinin içerisinde ele almışlardır.

Yönetim kapasitesi ürün veya hizmetlerin üretimi, sunumu ve teslimatı gibi işlevleri üstlenen ve bu yönüyle müşteri değeri yaratan bir işletme fonksiyonudur (Hammer ve Champy 1993). Müşteri ilişkileri kapasitesi, işletme ile müşteri arasında kurulan, satış öncesi ve satış sonrası tüm eylemleri kapsayan bir süreçtir (Odabaşı, 2004). Müşterilerin istek ve beklentilerinin belirlenmesi, müşterilerle en uygun ilişkilerin kurulmasını sağlamaktadır (Hooley vd., 2005). Han vd. (1998) pazar inovasyon kapasitesini, firmanın ürün ve hizmetlerinde yenilik yapma yeteneği olarak tanımlamışlardır. İnsan kaynakları değeri, müşteri memnuniyeti sağlamada ve organizasyon hedeflerine ulaşmada çalışanların bireysel potansiyellerinin geliştirilmesidir (Yang vd., 2011). İşletmelerin insan kaynakları sahip oldukları taklit edilememe, kendine has değerler taşıma ve olağanüstü özeliklere sahip olma gibi niteliklerinden dolayı sürdürülebilir rekabet avantajı elde etmenin kaynağı olabilmektedir (Wright vd., 1994). Son olarak firma ünü değeri ise işletmenin güvenilirliği ve tüketiciler, tedarikçiler ve dağıtımcılar 
arasındaki itibarını ifade etmektedir (Keller, 2001).

\subsection{Rekabet Stratejileri}

Kaynak temelli yaklaşıma göre bir firmanın rekabet avantajı sağlayabilmesi için bazı temel yeteneklere ve kaynaklara sahip olması gerekir (Lin vd., 2009). Yapılan bazı araştırmalar, firmaların sahip oldukları kaynaklar ile uyumlu stratejiler uygulamalarının, işletme performansı üzerinde pozitif etkilerinin olduğunu göstermektedir (Slater ve Narver, 1994; Panayides, 2004). Porter (1979), herhangi bir sektörde rekabet avantajı sağlamak ve rakipleri geride bırakmak için uygulanabilecek üç genel rekabet stratejisi olduğunu ileri sürmüştür. Bu stratejiler; maliyet liderliği, farklılaştırma ve odaklaşma stratejileridir.

Maliyet liderliği stratejisi, işletmelerin faaliyetlerini rakiplerinden daha az maliyetle yerine getirerek, sektör ortalamasının üzerinde kar elde etmesine yöneliktir (Porter, 2005). Bu stratejiyi uygulayan işletmeler toplam maliyetlerini en düşük düzeye indirmeyi amaçlarlar. Bunu başaran firmalar; maliyet avantajlarını kullanarak rakiplerin saldırılarına karşı güçlü bir savunma oluşturur, ortalamanın üzerinde bir karlılığa çıkar ve rakiplerin pazara girişlerine karşı caydırıcı bir rol oynar (Eser vd., 2011). Bunula birlikte piyasaya yeni giren firmalar için giriş engeli oluşturur, rakiplerine kıyasla daha yüksek bir pazar payına ve hammaddelere daha kolay erişim avantajına sahip olur (Barca ve Esen, 2012). Ancak maliyet liderliği stratejisi; ürün veya pazarlama faktörlerine ait değişkenlerin görülememesi, pazara yeni giren veya firma takipçilerinin düşük maliyetlemeyi öğrenmesi, teknolojik değişimlerin geçmiş yatırımları ve tecrübeleri etkisiz hale getirmesi ve işletmenin maliyet enflasyonu yaşaması gibi dezavantajlar taşımaktadır (Eren, 2014).

Porter'a (2005) göre sektörde rekabet edebilmenin diğer bir yolu da farklılaştırmadır. Ürün ve hizmette farklılaşma, rekabet avantajı oluşturmak isteyen işletmelerin en çok tercih ettikleri stratejiler arasında yer almaktadır (Güler, 2007). Farklılaştırma stratejisi, ürün ya da hizmetlerde diğer işletmelerden farklı uygulamalar yaparak rekabet avantajı sağlamaktır. İşletmeler farklılaştırma stratejisi uyguladıklarında rakiplerinden daha fazla müşteri beklentilerini karşılayarak daha yüksek fiyatlama yapabilirler. Bu şekilde sektör ortalamasının üzerinde bir gelir elde edebilirler. Ayrıca farklılaşma stratejisi uygulayan bir işletme marka bağlılığı yaratır ve talebin fiyat esnekliğini azaltır (Hill, 1988). Farklılaşma stratejisi, özellikle pazara giriş engellerinin yüksek olduğu koşullarda, tüketicilerin rakiplerinden farklı sunumlar gerçekleştiren işletmelere daha fazla ödeme yapmayı kabul etmeleri hem giriş engellerini anlamsızlaştırmakta hem de pazar payının düşük olmasının olumsuzluklarını azalmaktadır (Taşır, 2010).
Odaklanmış stratejiler ise pazar segmentasyonu yapılarak dar bir pazar platformunda belirli bir müşteri grubunun hedeflenmesidir. İşletmeler pazarı oldukça daraltarak ve farklı müşteri beklentilerine cevap vererek rekabet avantajı sağlayabilirler (Panayides, 2004). Pazarda rekabet eden işletme sayısının çok olduğu durumlarda, bazı orta ve küçük ölçekli işletmelerin şiddetli rekabete karşı koyabilmeleri için odaklanmış stratejiler birer kurtarıcı görevi üstlenmektedirler (Eser vd. 2011). Bu stratejinin uygulanabilmesi için ürünleri farklı şekilde isteyen ve kullanan değişik ihtiyaca sahip müşteri gruplarının bulunması, rakiplerin uzmanlaşmak yerine tüm müşterilere hizmet vermeyi seçmesi ve işletmelerin sahip olduğu sınırlı kaynaklarının ancak belli bir pazar bölümüne sunum gerçekleştirmeyi zorunlu kılması gibi koşulların bulunması gerekmektedir (Eren, 2014).

Literatürde çok kriterli karar verme yöntemleri ile otel işletmelerinin örnekleme alındığı birçok çalışma yapılmıştır (Murat ve Çelik, 2007; Atay ve Özdaloğlu, 2008; Coşar, 2008; Rouyendegh ve Erkan, 2010; Doğan ve Gencan, 2013; Ar vd., 2014; Doğan ve Karakuş, 2014; Karaatlı vd., 2014). Coşar (2008) rekabet gücü faktörlerini otel işletmeleri açısından incelemiştir. İşletme yöneticileri arasından seçilen bir örnek grup üzerinde yapılan çalışmada otel işletmelerin rekabet gücü üzerinde etkili olan faktörler belirlenmiştir. Murat ve Çelik (2007), analitik hiyerarşi süresi (AHS) yöntemi ile üç yıldızlı otelleri hizmet kalitesi kriterleri açısından karşılaştırmalı olarak değerlendirerek en iyi otel alternatifini tespit etmiştir. Atay ve Özdadaloğlu (2008), dört ve beş yıldızlı otellerin tüketim ürünleri gereksinimini sağladıkları tedarikçi seçimini etkileyen kriterleri AHS yöntemi ile belirlemiştir. AHS ve Veri Zarflama Analizinin birlikte kullanıldığı diğer bir çalışmada Rouyendegh ve Erkan (2010), dört yıldızlı otellerin etkinlik ölçümünü incelemişlerdir.

Turizm endüstrisinin önemli işletme türlerinden birisi olan seyahat acentelerine yönelik bir araştırmada, acente yöneticilerinin kendilerine en uygun gördükleri beş yıldızlı oteller bulanık AHS yöntemi ile belirlenmeye çalışılmıştır (Doğan ve Gencan, 2013). Coşkun vd. (2013) ise maliyet liderliği, odaklanma ve farklılaşma stratejileri açısından üç, dört ve beş yıldızlı otel işletmelerinin inovasyon stratejilerini ele almışlardır. Köroğlu (2013) otel işletmelerinin rekabet üstünlüğü elde etmelerini yönetim muhasebesi yöntemleri uygulaması açısından ele almış ve dört yıldızlı bir otel işletmesinde uygulama yapmıştır. Köseoğlu vd. (2013) üç, dört ve beş yıldızlı otel yöneticilerini örnekleme aldığı çalışmalarında Porter, Miles ve Snow'un rekabet stratejilerinden hangisinin oteller için en iyi seçenek olduğunu belirlemeye çalışmışlardır.

Turizm sektöründe çok kriterli karar verme yöntemlerinin kullanıldığı diğer çalışmalarda Doğan ve 
Karakuş (2014), kalite fonksiyon göçerimi ve AHS bütünleşik yöntemini kullanarak hizmet kalitesini, Karaatlı vd. (2014) AHS ve bulanık TOPSIS yöntemi ile beş yıldızlı bir otelin tur operatörü seçim sürecini, Ar vd. (2014) ise ekoturizm merkezi için yer seçim kararlarında etkili olan kriterleri bulanık AHS-VIKOR yaklaşımı ile ele almışlardır.

Bu çalışmalar değerlendirildiğinde, turizm alanında çok kriterli karar verme yöntemlerinin otellerin hizmet kalitesinin değerlendirilmesi, tedarikçi seçimi, etkinlik analizi, tur operatörü seçimi, acentelere göre en iyi otel seçimi ve kuruluş yeri seçimi amaçlarıyla kullanıldığı görülmektedir. Yerli alan yazında otel işletmelerinin pazarlama kaynakları ile rekabet stratejisi arasındaki ilişki bu çalışmada ele alınan şekli ile incelenmemiştir. Bu nedenle bu araştırma ile elde edilen sonuçların literatürde önemli bir boşluğu dolduracağı düşünülmektedir.

\subsection{Analitik Hiyerarşi Süreci (AHS)}

AHS 1980 yılında Thomas L. Saaty tarafından ortaya atılan ve çok kriterli karar problemlerinin çözümünde oldukça geniş bir uygulama alanı olan bir yaklaşımdır (Yang ve Huang, 2000; Hafeez vd., 2002; Yoon ve Im, 2005). AHS farklı ölçümlere dayalı (nitel veya nicel) kriter, yargı veya karar alternatiflerini tek bir değerde birleştirip önem açısından sıralamayı amaçlayan ve temel mantığı bu yargıların ikili olarak karşılaştırılması prensibine dayanan matematiksel bir yaklaşımdır (Chin ve Cheng, 2008).

AHS yönteminde yargıların ikili karşılaştırmaları, matrisler aracılığı ile yapılmaktadır. Ayrıca, karşılaştırma matrislerinin kendi içlerinde tutarlı olmaları gerekmektedir. Buradan hareketle, Saaty (2001)'e göre matrisler için bir uyum ölçüsü olan tutarlılık oranı, " $\mathrm{CR}=\mathrm{Cl} / \mathrm{Rl}$ " formülü ile hesaplanır. Formülde yer alana "CR", tutarlılık oranını; "Cl" tutarlılık indeksini ve son olarak, "RI", rastlantısal indeksi ifade etmektedir. "RI", rastlantısal olarak oluşturulan karşılaştırma matrislerinin, ortalama tutarlılık oranını gösteren sayısal değerlerdir (Kwiesielewicz ve Uden, 2004). Tablo 2.'de rastlantısal indeks değerleri gösterilmiştir.

Tablo 2. Rastlantısal İndeks Değerleri

\begin{tabular}{|l|l|l|l|l|l|l|l|l|}
\hline $\mathrm{n}$ & 1 & 2 & 3 & 4 & 5 & 6 & 7 & 8 \\
\hline R.I. & 0,00 & 0,00 & 0,52 & 0,89 & $1, .11$ & 1,25 & 1,35 & 1,40 \\
\hline $\mathrm{N}$ & 9 & 10 & 11 & 12 & 13 & 14 & 15 & \\
\hline R.I. & 1,45 & 1,49 & 1,51 & 1,48 & 1,56 & 1,57 & $1, .59$ & \\
\hline
\end{tabular}

Kaynak: Saaty ve Özdemir, 2003.

$C R^{\prime} ı n, n \geq 5$ için $C R \leq 0,1 ; n=4$ için $C R \leq 0,08$ ve $n=3$ için $C R \leq 0,05$ aralıklarında olması tavsiye edilmektedir (Chin ve Cheng, 2008).

AHS yaklaşımında değerlendirme süreci uzman grup kararına dayalı olarak çalışır. Bu süreçte 3 yön- tem kullanılabilir; (1) uzmanların bir kriter ya da yargı ile ilgili görüş birliğinde oldukları uzlaşma, (2) bir fikir birliğine varamadıkları durumda oy kullanma ve (3) geometrik veya aritmetik ortalama yaklaşımlarıdır (Melon vd., 2006). Bu çalışmada üçüncü yaklaşım olan geometrik ortalama yaklaşımı kullanıımıştır.

Üçüncü yaklaşımda, $a_{i j}^{k}, \mathrm{k}$. karar vericinin i. elementle j. elementi karşılaştırma değeri olmak üzere $\mathrm{n}$ tane karar vericinin kararı geometrik ortalama ile $a_{i j}=\left[a_{i j}^{1} * a_{i j}^{2} * \ldots * a_{i j}^{n}\right]^{1 / n}$ şeklinde bir değere indirgenir ve karşılaştırma değeri olarak belirlenir. Bu yaklaşım, diğerlerine göre daha fazla kabul gören yaklaşımlardan birisidir (Melon vd., 2008).

AHS yaklaşımında önemli olan bir başka konu ise hesaplamaların hangi yazılımla yapıldığıdır. Bu konuda birçok alternatif olmasına rağmen Super Decision, Expert Choice ve Microsoft Excel en çok kullanılan yazilımlardır (Demirtas ve Özden, 2008; Melon vd., 2008; Baby, 2013).

\subsection{Bulanık TOPSIS}

Bulanık TOPSIS, Chen vd. (2006) tarafından geliştirilen çok kriterli karar verme tekniklerinden biridir. Uzman kişiler tarafından dilsel değişkenler kullanılarak, kriter ve alternatifler değerlendirilir ve matematiksel işlemlerle sonuca ulaşılır. Bu çalışmada Bulanık TOPSIS yaklaşımı belirsizliği daha iyi ifade etmesi nedeniyle, çalışmanın son kısmında alternatiflerin değerlendirilmesi için kullanılmıştır. Tablo 3'te kullanılan dilsel değişkenler ve karşılıkları olan üçgen bulanık sayılar gösterilmiştir.

Tablo 3. Alternatiflerin Değerlendirilmesi İçin Kullanılan Dilsel Değişkenler

\begin{tabular}{|l|l|}
\hline Dilsel Ifade & Üçgen Bulanık Sayı Karşılıkları \\
\hline Çok Zayıf (ÇZ) & $(0002,5)$ \\
\hline Zayıf (Z) & $(02,55)$ \\
\hline Orta (O) & $(2,557,5)$ \\
\hline İyi (I) & $(57,510)$ \\
\hline Çok lyi (Çi) & $(7,51010)$ \\
\hline
\end{tabular}

Kaynak: Junior vd., 2014.

Dilsel ifadeler kriter ve alternatifleri belirsizlik altında değerlendirmek için karar vericiler (KV) tarafından kullanılır. Burada alternatiflerin KV'ler tarafından değerlendirilmesi için dilsel ifadeler kullanılmış ve Bulanık TOPSIS yardımıyla ağırlıklandııımıştır. Bulanık TOPSIS yöntemi için şu adımlar izlenebilir (Chen vd., 2006; Junior vd., 2014; Wang, 2014).

i) Kriterlerin ve alternatiflerin ortalama ağırlıklarının hesaplanmasıiçin $\mathrm{k}$ tane $\mathrm{KV}$ tarafından verilen puanların ortalaması alınır. 


$$
\begin{aligned}
& \tilde{W}_{j}=\frac{1}{k}\left[\begin{array}{cc}
\sim 1 & \sim \\
w_{j}+w_{j}+\ldots+w_{j}
\end{array}\right] \\
& \tilde{x}_{i j}=\frac{1}{k}\left[\begin{array}{l}
\sim 1 r \\
x_{i j}+x_{i j}+\ldots+x_{i j}
\end{array}\right]
\end{aligned}
$$

Burada; $\stackrel{\sim r}{w_{j}}$ r. KV tarafından atanan j. kriter ağırlığını $C_{j}(j=1, \ldots, m), \stackrel{\sim r}{x_{i j}}$ ise i. alternatifin puanını gösterir.

ii) Alternatif için $(D)$ kriterler için $(W)$ bulanık karar matrisi ise şu şekildedir.

$$
\begin{array}{r}
\tilde{D}=A_{2}\left[\begin{array}{ccc}
\tilde{x_{11}} & \cdots & \tilde{x}_{1 m} \\
A_{3} & \ddots & \vdots \\
\tilde{x_{n 1}} & \cdots & \tilde{x}_{n m}
\end{array}\right] \\
\tilde{W}=\left[\begin{array}{c}
\tilde{w_{1}}+\tilde{w}_{2}+\ldots+\tilde{w}_{m}
\end{array}\right]
\end{array}
$$

Bu çalışmada kriterler için karar matrisi AHS ile elde edilmiştir.

iii) Bulanık karar matrisi $(D)$ lineer ölçek dönüşümü kullanılarak normalize bulanık karar matrisi $(R)$ elde edilir.

$$
\begin{aligned}
& \tilde{R}=\left[\tilde{r}_{i j}\right]_{m^{* n}} \\
& \tilde{r}_{i j}=\left(\frac{l_{i j}}{u_{j}^{+}}, \frac{m_{i j}}{u_{j}^{+}}, \frac{u_{i j}}{u_{j}^{+}}\right) \text {ve } u_{j}^{+}=\max _{i} u_{i j} \\
& \tilde{r}_{i j}=\left(\frac{l_{j}^{-}}{u_{i j}}, \frac{l_{j}^{-}}{m_{i j}}, \frac{l_{j}^{-}}{l_{i j}}\right) \text { ve } l_{j}^{-}=\max _{i} l_{i j}
\end{aligned}
$$

iv) Ağırlıklı normalize karar matrisi, normalize edilen karar matririsinin ağırlık vektörü ile çarpımı sonucu elde edilmiştir. Bu çalışmada ağırlıklar AHS ile edildiğinden bulanık sayı değildir.

$$
\begin{aligned}
& \tilde{V}=\left[\tilde{v_{i j}}\right]_{m^{* n}} \\
& \tilde{v} \\
& v_{i j}=\tilde{x}_{i j} * w_{i j}
\end{aligned}
$$

v) Bulanık Pozitif İdeal Çözüm $A^{+}$ve Bulanık Negatif İdeal Çözüm A-Hesaplanır.

$$
A^{+}=\left\{\begin{array}{l}
\sim^{+} \tilde{v}^{+} \\
v_{1}, v_{j}^{+} \\
\end{array}\right\}
$$

$A^{-}=\left\{\begin{array}{l}\sim-\sim \\ v_{1}, v_{j}, \ldots, v_{m}\end{array}\right\}$

Burada; $\tilde{v_{j}}=(1,1,1)$ ve $\tilde{v_{j}}=(0,0,0)$ dır.

vi) Her alternatifin sırasıyla $\tilde{v}_{j}^{+}$ve $\tilde{v}_{j}$ den uzaklıkları $d_{j}^{+}$ve $d_{j}^{-}$hesaplanır.

$$
\begin{aligned}
& d_{j}^{+}=\sum_{j=1}^{n} d_{v}\left(\tilde{v}_{i j}, \tilde{v}_{j}^{+}\right) \\
& d_{j}^{-}=\sum_{j=1}^{n} d_{v}\left(\tilde{v_{i j}}, \tilde{v}_{j}\right)
\end{aligned}
$$

Burada "d" iki bulanık sayı arasındaki uzaklığın vertex metodu ile hesaplanmış halidir. Şu şekilde formülleştirilebilir:

$d(\tilde{x, z})=\sqrt{\frac{1}{3}\left[\left(l_{x}-l_{z}\right)^{2}+\left(m_{x}-m_{z}\right)^{2}+\left(u_{x}-u_{z}\right)^{2}\right]}$

vii) Son olarak yakınlık katsayısı hesaplanır.

$$
C C_{i}=\frac{d_{i}^{-}}{d_{i}^{+}+d_{i}^{-}}
$$

\section{UYGULAMA}

AHS ve Bulanık TOPSIS yöntemlerinin birleştirilmesinden oluşan yaklaşımın işleyişi şu şekildedir: (1) Seçim kriterlerinin belirlenmesi, (2) Seçim kriterlerinin AHS ile ağırlıklandırılması, (3) Bulanık TOPSIS yöntemi yardımıyla da alternatif stratejilerin önem düzeyi sıralanması.

Şekil 1.'de otel işletmelerinin rekabetçi pazarlama stratejisi seçiminde sahip olduğu pazarlama kaynakları ve rekabet stratejisi alternatifleri gösterilmektedir. Pazarlama kaynakları (Hooley vd. 2005); yönetim kapasitesi (YK), müşteri ilişkileri kapasitesi (MiK), pazar inovasyon kapasitesi (PIK), insan kaynakları değerleri (IKD) ve firma ünü değerleri (FÜD) boyutlarından oluşmaktadır. Literatürde otel işletmelerinin pazarlama kaynaklarının ele alındığı çalışmalarda, Hooley vd.'nin (2005) pazarlama kaynakları boyutlarının kullanıldığı görülmektedir (Lin ve Wu, 2008; Lin vd., 2009; Wu vd., 2010). Otel işletmelerinin rekabetçi pazarlama stratejisi seçimi için üç alternatif bulunmaktadır. Bunlar, odaklanma stratejisi (OS), farklılaşma stratejisi (FS) ve maliyet liderliği stratejisi (MLS) şeklindedir. Şekil 1' de AHS prensipleri doğrultusunda kurulan amaç, ana kriterler ve alternatiflerin yer aldığı hiyerarşik yapı oluşturulurken Lin ve Wu'nun (2008) yöntemi esas alınmıştır.

\subsection{Veri toplama}

Kış turizmine yönelik tesislerin bulunduğu illerde faaliyet gösteren otel işletmelerinin sahip oldukları pazarlama kaynaklarına en uygun rekabet stratejile- 
rinin seçimini amaçlayan bu araştırma kapsamında, veri temini sağlanması için uzman görüşlerine başvurulmuştur. Araştırmaya katılan uzmanlar, araştırmaya dâhil edilen otel işletmelerinin yöneticileri veya sahipleri olarak belirlenmiştir. Bunun nedeni, otel işletmelerinin yöneticileri veya sahiplerinin, kış turizmi faaliyetlerine yönelik, sahip oldukları bilgi birikimi ve deneyimleri ve otel işletmelerinin uyguladıkları stratejilerin belirlenmesinde en üst düzeyde karar verici konumunda olmalarıdır. Bu bağlamda, Kültür ve Turizm Bakanlığı́nın Yatııım ve İşletmeler Genel Müdürlüğü tarafından sunulan 2014 yılı verileri incelenmiştir. Bu verilere göre, Doğu Anadolu Bölgesi'nde yer alan Erzurum, Kars ve Erzincan illerinde Turizm Işletmesi Belgesi alan 3 yıldız ve üstü otel işletmelerinin sayısı 20'dir (Kültür ve Turizm Bakanlığı, 2014). Araştırmada, bu üç ilde yer alan otel işletmeleri temel alınmıştır. Bunun nedeni, son yıllarda bu illerde kış turizmine yönelik yatırımların oldukça yoğunlaşmasından dolayı bölgedeki kış turizmi faaliyetlerinin artmasıdır. Ayrıca maddi kaynak ve zaman kısıtları, araştırmayı belli bir bölgede sınırlandırmayı zorunlu kılmıştır. Belirlenen otellerden birer uzman araştırmaya dâhil edilmiştir. Yani toplamda 20 uzman ile görüşülmüştür. DeVellis'e (2012) göre, görüşleri alınacak uzman sayısının en az 5, en fazla 40 olması gerekmektedir. Bu nedenle, araştırmada 20 uzmanın görüşlerinin alınmasının yeterli olacağı düşünülmüştür. Araştırmaya dâhil edilen uzmanların pazarlama kaynaklarına göre en uygun strateji seçim kararlarını öğrenmek amacıyla anket formu hazırlanmıştır. Katılımcılarla yüz yüze görüşülerek, rekabetçi pazarlama stratejisi seçimi açısından pazarlama kaynaklarının birbirlerine üstünlükleri sorulmuştur. Ayrıca her bir pazarlama kaynağına göre rekabet stratejilerinin birbirlerine üstünlüklerini değerlendirmeleri istenmiştir. Anket formu 14-25 Nisan 2014 tarihleri arasında araştırmacılar tarafından uygulanmıştır. Görüşmeler yaklaşık olarak 1 saat sürmüştür.

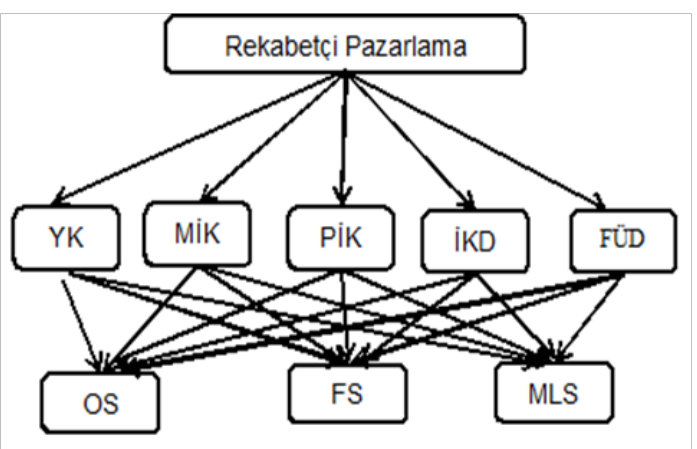

Şekil 1. Rekabetçi Pazarlama Stratejisi Seçim Hiyerarşisi

(YK: Yönetim kapasitesi, MiK: Müşteri ilişkileri kapasitesi, PiK: Pazar inovasyon kapasitesi, İKD: İnsan kaynakları değerleri, FÜD: Firma ünü değerleri)

Yapılan anket çalışması sonucunda, katılımcıların \%90'ının erkek, \%10'unun ise kadınlardan oluştuğu belirlenmiştir. Ayrıca katılımcıların, \%85'i lisans ve $\% 15$ i yüksek lisans mezunudur. Son olarak araştırma örneğine dâhil edilen işletmelerin tamamının faaliyet süreleri beş yıldan fazladır. Uzmanların seçim kriterlerine yönelik değerlendirmeleri, bir sonraki başlık altında verilmiştir.

\section{2. Seçim Kriterlerinin AHS İle Ağırıklandırııması}

Kriterlerin ağırlıklandırıması için AHS yöntemi uygulanmıştır. Uzmanlara uygulanan anketler doğrultusunda kriter ve alternatiflerin ikili karşılaştırma matrisleri elde edilmiş ve göreceli değerlendirmeler vasıtasıyla kriterlerin ağırılıkları belirlenmiștir. Yöntemin uygulanması için Super Decision paket programı kullanılmıştır. Aşağıda kriterlerin ve bir kriter açısından alternatif pazarlama stratejilerinin karşılaştırma matrisleri verilmiştir.

Otel işletmelerinin pazarlama kaynaklarının ikili karşılaştırmasını gösteren Tablo 4 incelendiğinde, rekabet avantajı üzerinde en büyük etkide bulunan kriterin 0,361 özvektör değeri ile müşteri ilişkileri kapasitesi olduğu görülmektedir. İkinci sırada etkili olan kriter ise 0,272 özvektör değeri ile yönetim kapasitesi kriteridir. Rekabet avantajı sağlamada etki gücü en zayıf olan kriterler ise 0,096 özvektör değerleri ile insan kaynakları değerleri ve pazar inovasyon kapasitesi olmuştur. Yapılan bütün ikili karşılaştırmaların tutarlıı̆ıını veren $\mathrm{CR}$ oranı kabul edilebilir sınırda hesaplanmıştır. Tablo 4'te karar vericilerin tamamından elde edilen değerlendirmelerin geometrik ortalaması verilmiştir. AHS ile bütün kriter ve alternatiflerin ikili karşılaştırmaları yapılmaktadır. Ancak bu araştırmada Bulanık TOPSIS için sadece kriter ağırlıklarına intiyaç duyulduğundan, alternatifler için karşılaştırma matrisleri verilmemiştir.

AHS ile elde edilen ağırıklar TOPSIS yönteminde, ağırlıklı normalize matrisin oluşturulması için kullanılmıştır. AHS ile elde edilen ağırlıklar, Amiri (2010) ve Yu vd.'nin (2011) çalışmalarında olduğu gibi bulanıklaştırılmadan kullanılmıştır.

\subsection{Bulanık TOPSIS Yöntemi Yardımıyla Alternatif Stratejilerin Önem Düzeyi Sıralaması}

Çalışmada AHS ve Bulanık TOPSIS yaklaşımları için ayrı ayrı veri toplanmıştır. Bulanık TOPSIS için dilsel ifadeler, AHS için ise göreli önem ölçeği kullanılmıştır. $\mathrm{Bu}$ aşamada AHS ile elde edilen kriter ağırlıkları ve alternatiflerin dilsel ifadeler aracılığıyla karşılaştırılması ve elde edilen karar matrisinin Bulanık TOPSIS yaklaşımıyla analiz edilmesi sonucunda alternatiflerin önem düzeyinin sıralaması gerçekleştirilmiştir. Tablo 5'de, karar vericiler tarafından dilsel ifadelerle değerlendirilen alternatiflerin pazarlama kaynakları kriterleri açısından performanslarını gösteren karar matrisi verilmiştir. Tabloda karar vericilerin pazarlama kaynakları-alternatif rekabet srtajileri değerlendirmelerine örnek oluşturması açısından sadece üç karar verici gösterilmiştir. 
Tablo 4. Nihai Hedef Açısından Kriterlerin İkili Karşılaştırma Matrisi

\begin{tabular}{|l|l|l|l|l|l|l|}
\hline Kriterler & YK & MiK & PiK & IKD & FÜD & Kriter Ağırlıkları \\
\hline YK & 1 & 0,753 & & & & \\
\hline & 2,8083 & 2,8083 & 1,5731 & 0,27204 & & \\
\hline MiK & 1,3280 & 1 & 3,7296 & 3,7296 & 2,0892 & 0,36129 \\
\hline & & & & & & \\
\hline PiK & 0,356 & 0,268 & 1 & 1 & 0,56 & 0,09687 \\
\hline IKD & 0,356 & 0,268 & 1 & 1 & 0,56 & 0,09687 \\
\hline FÜD & 0,635 & 0,478 & 1,7851 & & & \\
\hline & 1,7851 & 1 & 0,17293 & & & \\
\hline
\end{tabular}

$C R=0,001<0,10$

Tablo 5. Alternatiflerin Dilsel İfadelere Göre Değerlen-

Tablo 5'te verilen değerlendirme matrisi her bir dirme Matrisi

\begin{tabular}{|c|c|c|c|c|}
\hline Kriter & Alternatif & KV1 & KV2 & KV3 \\
\hline \multirow{3}{*}{ YK } & FS & 0 & o & 0 \\
\hline & OS & z & 0 & z \\
\hline & MLS & Çi & i & Çi \\
\hline \multirow{3}{*}{ MiK } & FS & $i$ & 0 & $i$ \\
\hline & OS & Çi & çi & Çi \\
\hline & MLS & z & ÇZ & 0 \\
\hline \multirow{3}{*}{ PIK } & FS & $i$ & $\mathrm{i}$ & çi \\
\hline & OS & 0 & 0 & 0 \\
\hline & MLS & z & z & z \\
\hline \multirow{3}{*}{ IKD } & FS & 0 & i & $i$ \\
\hline & OS & 0 & 0 & 0 \\
\hline & MLS & z & $z$ & z \\
\hline \multirow{3}{*}{ FÜD } & FS & Çi & $i$ & $i$ \\
\hline & OS & $i$ & 0 & 0 \\
\hline & MLS & 0 & z & $\mathrm{Z}$ \\
\hline
\end{tabular}
karar verici için düzenlenmiştir. Matristeki dilsel ifadeler, Tablo 3'te verilen bulanık ölçek yardımıyla bulanık üçgen sayılara dönüştürülmüş ve (2) numaralı formül vasıtasıyla ortalamaları alınarak 20 karar vericinin tercihleri tek bir karar matrisi olarak birleştirilmiştir. Tablo 5'te sadece üç karar vericinin alternatifler için verdikleri puanlar görülmektedir. Hesaplamalarda ise 20 karar vericinin değerlendirmeleri bulanık sayılara dönüştürülmüş ve işlemler yapılmıştır.

Tablo 6'da ortak karar matrisinin üçgen bulanık sayılara dönüştürülmüş şekli verilmiştir.

Tablo 6. Üçgen Bulanık Sayılara Dönüştürülmüş Ortalama Matris

\begin{tabular}{|c|c|c|c|c|c|c|c|c|c|c|c|c|c|c|c|}
\hline & \multicolumn{3}{|c|}{ YK } & \multicolumn{3}{|c|}{ Мік } & \multicolumn{3}{|c|}{ PIK } & \multicolumn{3}{|c|}{ İKD } & \multicolumn{3}{|c|}{ FÜD } \\
\hline FS & 3,75 & 6,25 & 8,25 & 4,37 & 6,87 & 8,75 & 6,37 & 8,87 & 10 & 5 & 7,5 & 9,5 & 6 & 8,5 & 9,87 \\
\hline OS & 3,12 & 5,62 & 7,75 & 6,12 & 8,62 & 9,5 & 3,12 & 5,62 & 8,12 & 3,5 & 6 & 8,5 & 3,75 & 6,25 & 8,75 \\
\hline MLS & 3,25 & 5,75 & 7,5 & 0,87 & 2,62 & 5 & 0,37 & 2,25 & 4,75 & 0,6 & 3 & 5,37 & 0,75 & 3,12 & 5,62 \\
\hline
\end{tabular}

Üçgen bulanık sayılarla oluşturulmuş karar matrisi normalize edilmiş ve Tablo 7' de gösterilmiştir. Tablo 7'deki hesaplamalar (5), (6) ve (7) numaralı formüller aracılığıyla hesaplanmıştır.

Tablo 7. Normalize Karar Matrisi

\begin{tabular}{|c|c|c|c|c|c|c|c|c|c|c|c|c|c|c|c|}
\hline & \multicolumn{3}{|c|}{ YK } & \multicolumn{3}{|c|}{ MiK } & \multicolumn{3}{|c|}{ PIK } & \multicolumn{3}{|c|}{ İKD } & \multicolumn{3}{|c|}{ FÜD } \\
\hline FS & 0,45 & 0,75 & 1 & 0,46 & 0,72 & 0,92 & 0,85 & 1,18 & 1,33 & 0,5 & 0,8 & 1 & 0,61 & 0,86 & 0,99 \\
\hline OS & 0,37 & 0,68 & 0,93 & 0,64 & 0,90 & 1 & 0,41 & 0,75 & 1,08 & 0,4 & 0,6 & 0,89 & 0,38 & 0,63 & 0,88 \\
\hline MLS & 0,39 & 0,69 & 0,90 & 0,09 & 0,27 & 0,52 & 0,05 & 0,3 & 0,63 & 0,1 & 0,3 & 0,56 & 0,08 & 0,31 & 0,56 \\
\hline
\end{tabular}

Normalize karar matrisi AHP ile elde edilen kriter ağırlıkları ile (8) ve (9) numaralı formüller kullanılarak ağırlıklı normalize matris haline dönüştürülmüştür (Tablo 8). 
Tablo 8. Ağırlıklı Normalize Matris

\begin{tabular}{|c|c|c|c|c|c|c|c|c|c|c|c|c|c|c|c|}
\hline & \multicolumn{3}{|c|}{ YK } & \multicolumn{3}{|c|}{ MiK } & \multicolumn{3}{|c|}{ PIK } & \multicolumn{3}{|c|}{ İKD } & \multicolumn{3}{|c|}{ FÜD } \\
\hline FS & 0,12 & 0,20 & 0,27 & 0,17 & 0,3 & 0,33 & 0,08 & 0,11 & 0,12 & 0,05 & 0,07 & 0,09 & 0,10 & 0,14 & 0,17 \\
\hline OS & 0,10 & 0,18 & 0,25 & 0,23 & 0,33 & 0,36 & 0,04 & 0,07 & 0,10 & 0,03 & 0,06 & 0,08 & 0,06 & 0,10 & 0,15 \\
\hline MLS & 0,11 & 0,19 & 0,24 & 0,03 & 0,10 & 0,19 & 0,005 & 0,02 & 0,06 & 0,006 & 0,03 & 0,05 & 0,01 & 0,05 & 0,09 \\
\hline
\end{tabular}

Tablo 9'da otel sahip/yöneticilerinin değerlendirmeleri doğrultusunda rekabet stratejilerinin sıralaması gösterilmektedir. Bulanık TOPSIS yöntemi ile yapılan hesaplamaya göre rekabetçi pazarlama stratejileri arasında ilk sırada farklılaşma stratejisi, ikinci sırada odaklanma stratejisi ve son sırada maliyet liderliği stratejisi bulunmaktadır.

Tablo 9. Alternatif Stratejilerin BulanıkTOPSIS Sıralaması

\begin{tabular}{|c|c|c|c|c|}
\hline & $\mathrm{d}+$ & $\mathrm{d}-$ & $\mathrm{CC}$ & Siralama \\
\hline FS & 6,551 & 1,126 & 0,148 & 1 \\
\hline OS & 6,627 & 1,0564 & 0,137 & 2 \\
\hline MLS & 7,129 & 0,583 & 0,076 & 3 \\
\hline
\end{tabular}

Tablo 9'da yer alan "d+" ve "d-" uzaklıkları (12) ve (13) numaralı formüllerle, iki bulanık sayı arasındaki uzaklık $(d(x, z))(14)$ numaralı formülle vertex metoduna göre ve "CC" yakınlık katsayısı ise (15) numaralı formülle hesaplanmıştır.

\section{SONUÇ}

Bu araştırmada Doğu Anadolu Bölgesi'nde kış turizmi yapılan illerde 3 yıldız ve üstü otel işletmelerinin pazarlama kaynaklarına göre rekabetçi pazarlama stratejisi seçim süreci ele alınmıştır. 20 uzmandan alınan görüşlerin analiz edilmesi sonucunda, otel işletmelerinin rekabet avantajı elde etmelerinde en etkili olan pazarlama kaynağının müşteri ilişkileri kapasitesi olduğu tespit edilmiştir. Müşteri ilişskileri kapasitesi; müşteri hizmet ve desteğinin üst düzeyde olması, müşteri ihtiyaç ve taleplerinin anlaşılması, müşterilerle iyi ilişkiler kurulması ve bu ilişkilerin sürdürülmesini ifade eder (Hooley vd., 2005). Benzer şekilde Sigala (2005), müşteri ilişkileri kapasitesinin işletmelerin rekabet avantajlarını sürdürebilmeleri için çok önemli bir yerinin olduğunu vurgulamıştır. Otel işletmelerine yönelik çalışmalarda, müşteri iliş̧kileri kapasitesinin işletme performansı (Wu ve Li, 2011; Wu ve Chen, 2012; Josiassen vd., 2014), müşteri bağlılığı ve satın alma niyeti (Wu ve Li, 2011) üzerine olumlu etkisinin olduğu ifade edilmiştir. Bu çalışmadan elde edilen sonuçlarda, işletmelerin rekabet avantajı elde etmelerinde en çok etkisi olan pazarlama kaynağının müşteri ilişkileri kapasitesi olduğu belirlenmiştir. Bu sonuç, literatürü destekler niteliktedir. Buradan hareketle, otel yöneticilerin rekabet avantajı yakalayabilmeleri için müşteri ihtiyaç ve beklentilerini doğru anlamaları, onlara üst düzeyde müşteri hizmetleri sunmaları ve en önemli müşterilerle ilişkilerini geliştirmeleri gerekmektedir.

Otel işletmelerinin rekabet avantajı yakalamaların- da etkili olan ikinci faktör yönetim kapasitesidir. Otel işletmelerinin sahip olduğu finansal kaynaklar, insan kaynaklarının etkinliği, operasyon yönetim uzmanlarının kapasitesi ve hizmet yönetim süreçleri yönetim kapasitesini oluşturur (Hooley vd., 2005). Kış turizminin bulunduğu illerde otel işletmelerinin finansal kaynakları ve hizmet işletmelerinin temel karma unsurlarından biri olan personel kapasitesi, rekabet üstünlüğü açısından önemli görülmektedir.

Araştırmada elde edilen diğer bir sonuç otel yönetici/sahiplerine göre rekabetçi pazarlama stratejisi uygulamanın farklılaşma stratejisi ile gerçekleşebileceğidir. Farklılaştırma stratejisi, işletmelerin ürün ya da hizmetlerde diğer işletmelerden farklı uygulamalar yapması, rakiplerinden daha fazla müşteri beklentilerini karşılayarak daha yüksek fiyatlama yapabilmesi ve bu sayede sektör ortalamasının üzerinde bir gelir elde edebilmesidir. Otel işletmeleri için farklılaşma, müşterilere sunulan hizmet unsurlarının geliştirilmesi ve rakiplerinden daha kaliteli hizmetler sunması ile gerçekleşebilir. Müşterilerin hizmet kalitesi algıları otel işletmesini rakiplerinden ayıran sunumları içermektedir. Spor turistleri kayak merkezlerini değerlendirirken en fazla kayak eğitmenlerine, kayak pistleri - malzemelere ve otel ve çalışanlarına önem vermektedirler (Gençer vd., 2008). Bu unsurlar aynı zamanda işletmelerin rakiplerinden farklılaşmak için kullanabileceği hizmet sunum boyutlarını içermektedir. Ayrıca bir otel işletmesinin kendisine has özellikleri ile müşterilerine değer yaratması farklılaşma için önemli olan diğer bir konudur. Otel işletmeleri hizmet inovasyonu, yaratıcı reklam, tedarikçilerle kurulan iyi ilişkilerin sonucu olarak müşterilerine daha iyi hizmet verebilmesi sayesinde pazarlama kaynaklarına uygun eşsiz sunumlar gerçekleştirebilir. Otel yöneticilerinin bu unsurlara önem vermesinin rekabet üstünlüğü yakalamalarına katkı sağlayacağı beklenilmektedir.

Araştırmanın kış turizminin faaliyetlerinin yapıldığı 3 ilde yürütülmüş olması, çalışmanın en önemli kısıtını oluşturmaktadır. Bu nedenle ileride yapılacak olan çaIışmalarda bulanık AHS ve bulanık TOPSIS yaklaşımları hibrit yöntemler olarak kullanılıp analizler yapılabilir. Örneklem büyüklüğü arttırılıp farklı bölge ve illerde uzman görüşünü değerlendiren anketler uygulanabilir. Ayrıca kış turizminin olduğu illerin turizm potansiyellerini daha iyi değerlendirebilmek için II Turizm Müdürlükleri, Belediye Başkanları, Valilik, Ticaret ve Sanayi Odaları gibi sektörün diğer paydaşlarının da örnekleme alındığı en uygun rekabet stratejisi belirleme çalışmaları yapılabilir. 
Alternatif rekabet stratejilerinin sıralanmasında odaklanma stratejisi ile farklılaşma stratejisi değerlerinin birbirine yakın olduğu görülmüştür. Bu sonuca örnekleme alınan otellerin üç yıldız ve üstü gruba ait olmasının neden olduğu düșünülmektedir. Diğer bir ifadeyle farklı sınıflardaki otellerin sahip oldukları pazarlama kaynaklarının birbirlerinden farklı olmalarından dolayı ileriki araştırmalarda aynı sınıfta yer alan otellerin örnekleme alınmasının sıralama değerlerini farklılaştıracağı beklenilebilir.

\section{KAYNAKLAR}

Amiri, M. P. (2010). Project Selection for Oil-Fields Development by Using The AHP and Fuzzy TOPSIS Methods. Expert Systems with Applications, 37(9), 6218-6224.

Ar, İ. M., Baki, B. ve Özdemir, F. (2014) "Kuruluş Yeri Seçiminde Bulanık AHS-VIKOR Yaklaşımının Kullanımı: Otel Sektöründe Bir Uygulama” Uluslararası İktisadi ve İncelemeler Dergisi, 7(13). 93-114.

Atay L. Ve Özdağoğlu A. (2008) "Analitik Hiyerarşi Süreci (AHS) Yöntemiyle Tedarikçi Seçimini Etkileyen Faktörlerin Önem Düzeylerinin Belirlenmesi: Otel İşletmelerinde Bir Araşıırma” Seyahat ve Turizm Araştırmaları Dergisi.

Baby S., (2013) "AHP Modeling for Multicriteria Decision-Making and to Optimise Strategies for Protecting Coastal Landscape Resources" International Journal of Innovation, Management and Technology, 4 (2):218-227.

Barca, M. Ve Esen Saban (2012) "Rekabet Avantaj1 Sağlama Ve Sürdürmede Stratejik Yaklaşımlar” E-Journal Of New World Sciences Academy, 7(2):89-107.

Barney, J. (1991) "Firm Resources and Sustained Competitive Advantage" Journal of Management, 17: 99-120.

Barney, J. B. (1986) "Strategic Factor Markets: Expectations, Luck, and Business Strategy" Management Science, 32: 1231-1241.

Büyüközkan, G. ve Çifçi, G. (2012). A combined fuzzy AHP and fuzzy TOPSIS based strategic analysis of electronic service quality in healthcare industry.Expert Systems with Applications, 39(3), 2341-2354.

Chen, C. T. Lin, C. T. ve Huang, S. F. (2006) "A Fuzzy Approach for Supplier Evaluation and Selection in Supply Chain Management" International Journal Of Production Economics, 102 (2): 289-301.

Chin, T. L. ve Cheng, S. W. (2008) "Selecting a Marketing Strategy For Private Hotels in Taiwan Using the Analtic Hierarchy Process" The Service Industries Journal, 28 (8): 1077-1091.

Coşar, Y. (2008) "Otel İşletmelerinde Rekabet Üstünlüğünü Etkileyen Faktörler: Yöneticiler Üzerine Bir Araştırma” Anatolia: Turizm Araşıtımaları Dergisi, 19 (1): 45-56.
Coşkun, S. Mesci, M. ve Kılınç, İ. (2013) "Stratejik Rekabet Üstünlüğü Sağlama Aracı Olarak İnovasyon Stratejileri: Kocaeli Otel İşletmeleri Üzerine Bir Araştırma” Abant İzzet Baysal Üniversitesi Sosyal Bilimler Enstitüsü Dergisi, 13:101-132

Demirtas, E. A. ve Özden, Ü. (2008) "An Integrated Multiobjective Decision Making Process for Supplier Selection and Order Allocation” Omega, 36 (1): 76-90.

Deshpande, R. ve Frederick, E. W. (1989) "Organizational Culture and Marketing: Defining the Research Agenda" Journal of Marketing, 53: 3-15.

DeVellis, R. F., (2012) Scale Development: Theory and Applications (Vol. 26). Sage Publications.

Doğan, N. Ö. ve Gencan, S. (2013) "Seyahat Acentesi Yöneticilerinin Bakış Açısıla En Uygun Otel Seçimi: Bir Analitik Hiyerarşi Prosesi (AHP) Uygulaması" Erciyes Üniversitesi İktisadi ve İdari Bilimler Fakültesi Dergisi, 41(1): 69-88

Doğan, N. Ö. ve Karakuş Y. (2014) "KFG-AHP Bütünleşik Yöntemi Kullanılarak Turizm Sektöründe Hizmet Kalitesinin Değerlendirilmesi: Göreme Açı Hava Müzesi Üzerine Bir Uygulama” Süleyman Demirel Üniversitesi İ̈BF Dergisi. 19(3): 169-194.

Eren, M. Ş. (2014) "Jenerik Rekabet Stratejilerinin Firmaların İhracat Performansına Etkisi” Journal of Yasar University, 9(34): 5998-6022.

Eser, Z., Korkmaz, S. ve Öztürk, S. A. (2011) Pazarlama Kavramlar-İlkeler-Kararlar Ankara: Siyasal Kitabevi.

Gençer, R.T., Demir, C., Aycan, A., (2008) "Kayak Merkezlerindeki Spor Turistlerinin Hizmet Kalitesi Algılarını Etkileyen Değişkenler” Ege Akademik Bakış, 8(2):437-450.

Gupta, S. ve Steenburgh, T.J. (2008) "Allocating Marketing Resources", Harvard Business School Marketing Research Paper No. 08-069.

Güler S. (2007) "Yiyecek ve İçecek İşletmeleri İçin Rekabet Avantajı Yaratacak Stratejik Seçenekler” Anatolia Turizm Araştırmaları Dergisi, 18(1): 101-104.

Hafeez, K., Zhang, Y. B. ve Malak, N. (2002) "Determining Key Capabilities of A Firm Using Analytic Hierarchy Process", International Journal of Production Economics, 76 (1): 39-51.

Hammer, M. ve Champy, J. (1993) Business Process Re-Engineering. London: Nicholas Brealey.

Han, J. K., Kim, N. ve Srivastava, R. K. (1998) "Market Orientation and Organizational Performance: Is Innovation a Missing Link ?” Journal of Marketing, 62: 30-45.

Hill, C. W. (1988) "Differentiation Versus Low Cost Or Differentiation And Low Cost: A Contingency Framework" Academy of Management Review, 13(3): 401412. 
Hooley, G. J., Greenley, G. E., Cadogan, J. W. ve Fahy, J. (2005) "The Performance Impact of Marketing Resources" Journal of Business Research, 58: 18-27.

Hunt, S. D. ve Morgan, R. M. (1995) "The Comparative Advantage Theory of Competition", Journal of Marketing, 59: 1-15.

Josiassen, A., Assaf, G. ve Cvelbar, L. K. (2014) "CRM and the Bottom Line: Do All CRM Dimensions Affect Firm Performance?" International Journal of Hospitality Management, 36: 130-136.

Junior, F. R. L. ve Carpinetti, L. C. R. (2014) "A comparison between Fuzzy AHP and Fuzzy TOPSIS Methods to Supplier Selection" Applied Soft Computing, 21: 194209.

Karaatl, M., Ömürbek, N., Aksoy, E. ve Karakuzu, H. (2014) "Turizm İşletmeleri İçin AHP Temelli Bulanık TOPSIS Yöntemi ile Tur Operatörü Secimi” Anadolu Üniversitesi Sosyal Bilimler Dergisi. 14(2): 53-70.

Keller, K. L. (2001) "Building Customer-Based Brand Equity : A Blueprint for Creating Strong Brands Building Customer-Based Brand Equity : A Blueprint for Creating Strong Brands" Marketing Management, 10: 15-19.

Kozlenkova, I. V., Samaha, S. A ve Palmatier, R. W. (2014) "Resource-Based Theory in Marketing", Academy of Marketing Science, 42: 1-21.

Köroğlu, Ç. (2013) “Otel İşletmelerinde Rekabet Üstünlüğü Elde Etmek İçin Bir İleri Yönetim Muhasebesi Yöntemi Olarak Faaliyet Tabanlı Maliyetleme Yönteminin Analizi" Muhasebe ve Finansman Dergisi, Ocak:39-56.

Köseoglu, M. A., Topaloğlu, C., Parnell, J. A. ve Lester, D. L. (2013) "Linkages Among Business Strategy, Uncertainty And Performance In The Hospitality Industry: Evidence From An Emerging Economy" International Journal of Hospitality Management, 34: 81-91.

Kültür ve Turizm Bakanlığı Yatırım ve İşletmeler Genel Müdürlüğü (01/03/2014), Turizm Tesisleri Listesi, http://www.ktbyatirimisletmeler.gov.tr/TR,9579/turizmtesisleri-islemleri.html sitesinden alınmışır.

Kwiesielewicz, M. ve Uden, E. V. (2004) "Inconsistent and Contradictory Judgements in Pairwaise Comparison Method in The AHP” Computers \& Operations Research, 31 (5): 713-719.

Lin, C. T. ve Wu, C. S. (2008) "Selecting a Marketing Strategy for Private Hotels in Taiwan Using the Analytic Hierarchy Process" The Service Industries Journal, 28: 1077-1091.

Lin, C. T., Lee, C. ve Wu, C. S. (2009) "Expert Systems with Applications Optimizing a Marketing Expert Decision Process for the Private Hotel" Expert Systems with Applications, 36 (3): 5613-5619.
Lippman, S. A. ve Rumelt R. P. (1982) "Uncertain Imitability: An Analysis of Interfirm Differences in Efficiency under Competition" The Bell Journal of Economics, 13: 418-438.

Manap, G. (2006) "Analitik Hiyerarşi Yaklasımı ile Turizm Merkezi Seçimi” Ticaret ve Turizm Egitim Fakültesi Dergisi, 2: 157-1570.

Melon, M. G., Beltran, P. A. ve Cruz, M. C. G. (2006) "An AHP -Based Evaluation Procedure for Innovative Educational Projects: A Face to Face vs. Computer Mediated Case Study" Omega The International Journal of Management Science, 36 (5): 754-765.

Murat, G., Çelik, N. (2012) "Analitik Hiyerarşi Süreci Yöntemi İle Otel İşletmelerinde Hizmet Kalitesini Değerlendirme: Bartın Örneği” Uluslararası Yönetim İktisat ve İşletme Dergisi, 3(6):1-20.

Odabaşı, Y. (2004) Satışta ve Pazarlamada Müşteri İlişkileri Yönetimi İstanbul: Sistem Yayınclık.

Özdemir, M. S. (2005) "Validity and Inconsistency in the Analytic Hierarchy Process" Applied Mathematics and Computation, 161: 707-720.

Panayides, P. M. (2004) "Logistics Service Providers: An Empirical Study of Marketing Strategies and Company Performance" International Journal of Logistics: Research \& Applications, 7: 1-15.

Penrose, E. (1996) The Theory of the Growth of the Firm, Oxford: Oxford Universty Press.

Phillips, P. A., Margaret, D. F. ve Luiz, M. (2001) "The Interactive Effects of Strategic Marketing Planning and Performance: A Neural Network Analysis" Management Decision, 17: 279-288.

Porter, M. (1979) "How Competitive Forces Shape Strategy”, Harvard Business Review, 1979 (2): 137-145.

Porter, M. (2005) "Michael Porter on Strategy", Leadership Excellence, 22 (6): 14.

Reed, R.ve Defillippi, R. J. (1990) “ Causal Ambiguity, Barriers to Imitation, and Sustainable Competitive Advantage" Academy of Management Review, 15: 88102.

Rouyendegh, B. D. Ve Erkan, T. E. (2010) "Ankara'da Bulunan 4 Yıldızlı Otellerin, Vza-Ahs Sıralı Hibrit Yöntemiyle Etkinlik Değerlendirmesi” İktisadi ve İdari Bilimler Fakültesi Dergisi, 12(3), 1-22.

Saaty T. L. (1980) The Analytical Hiyerarchy Process, Mc Grow-Hill Company, New York.

Saaty, T. L. (1994) "How to Make a Decision: The Analytic Hierarchy Process" Interfaces, 24: 19-43.

Saaty, T. L., ve Ozdemir, M. S. (2003). Why The Magic Number Seven Plus or Minus Two. Mathematical and Computer Modelling, 38(3), 233-244. 
Saaty, T. L. (2008) "Decision Making with the Analytic Hierarchy Process" International Journal of Services Sciences, 1: 83-98.

Sigala, M. (2005) "Integrating Customer Relationship Management in Hotel Operations: Managerial and Operational Implications" International Journal of Hospitality Management, 24 (3): 391-413.

Slater, S. F. ve Narver, J. C. (1994) “Does Competitive Environment Moderate the Market Orientation-Performance Relationship?” Journal of Marketing, 58: 46-55.

Srivastava, R. K. (1998) "Market-Based Assets and Shareholder Value : A Framework for Analysis MarketBased Assets Shareholder Value : A Framework for Analysis" The Journal of Marketing, 62 (1): 2-18.

Tayşir, E. A. (2010) "Bir İşletmenin Uyguladığı Farklılaştırma Stratejisinin Pazarın Kurumsal Değişimi Üzerindeki Etkisi: Türkiye Kupon Pazarı Örneği” Öneri Dergisi, 9(34):163-172.

Udo, G. G. (2000) "Using Analytic Hierarchy Process to Analyze the Information Technology Outsourcing Decision" Industrial Management \& Data Systems, 100: 421-429.

Wang, Y. J. (2014) “The evaluation of financial performance for Taiwan container shipping companies by fuzzy TOPSIS” Applied Soft Computing, 22: 28-35.

Wernerfelt, B. (1984) "A Resource-Based View of the Firm” Strategic Management Journal, 5: 171-80.

Wright, P. M., McMahan, G. C. ve Mc Williams, A. (1994) "Human Resources And Sustained Competitive Advantage: A Resource-Based Perspective" International Journal Of Human Resource Management, 5(2), 301326.
Wu, C. S., Lin, C. T. ve Lee, C. (2010) “Optimal Marketing Strategy: A Decision-Making With ANP and TOPSIS" International Journal of Production Economics, 127(1), 190-196.

Wu, S. I. ve Chen, J. H. (2012) "Comparison between Hotels and Motels Using CRM Effect Model - An Empirical Study in Taiwan", International Journal of Hospitality Management, 31 (4): 1254-1263.

Wu, S. I. ve Li, P. C. (2011) "International Journal of Hospitality Management The Relationships between CRM , RQ, and CLV Based on Different Hotel Preferences" International Journal of Hospitality Management, 30(2): 262-271.

Yang, C. Ve Hunag, J. B. (2000) “A Decision Model for IS Outsourcing” International Journal of Information Management, 20 (3): 225-239.

Yang, M. G., Hong, P. ve Modi, S. B. (2011) "Impact of Lean Manufacturing and Environmental Management on Business Performance: An Empirical Study of Manufacturing Firms" International Journal of Production Economics, 129: 251-261.

Yoon, K. Y. ve Im, K. S. (2005) "An Evaluating System for IT Outsourcing Customer Satisfaction Using The Analytic Hierarchy Process" Journal of Global Information Management, 13 (4): 55-78.

Yu, X., Guo, S., Guo, J., \& Huang, X. (2011). Rank B2C e-commerce websites in e-alliance based on AHP and fuzzy TOPSIS. Expert Systems with Applications, 38(4), 3550-3557. 
